http://dx.doi.org/10.21611/qirt.1992.021

\title{
Thermographic characterisation of defects and failure in polymer composites
}

\author{
by M. BAUER, Ch. GUNTRUM, M. OTA, W. RIPPEL and G. BUSSE (*)
}

Institut für Kunststoffprüfung und Kunststoffkunde, Universität Stuttgart, Pfaffenwaldring 32, W-7000 Stuttgart 80, Germany.

\begin{abstract}
Vibrothermography is compared to heat flow methods and then applied to analyse the history of a failure starting from an artificial defect in laminates of glass fibre reinforced polymers (GFRP) or carbon fibre reinforced polymers (CFRP). The development of failure depends both on the kind of material and the laminate structure. Thermal instability "ping-pong-effect" could be observed immediately before failure in $\pm 45^{\circ} \mathrm{CFRP}$ laminate.
\end{abstract}

\section{Introduction}

Industrial specifications often result in the requirement to have more safety at less weight. Polymer materials are considered under this aspect due to their low density and high specific strength. However, in demanding applications the failure of a component may be much more expensive than the component itself. Therefore quality control aims at defect detection and analysis of failure mechanism. In this concept non destructive evaluation methods play a major role since they allow to monitor realistic or simulated processes without affecting the component under investigation.

Thermography is a technique which is often used for NDE. The basic idea is that heat is generated in or on the component, and that the resulting temperature field is imaged by the related infrared thermal emission where defects reveal themselves from the field distortion induced by them. Compared to ultrasonics, thermography has the advantage of being a noncontacting technique. An advantage compared to $X$-rays and laser techniques is the ease of application with no safety problems. Further advantages for the inspection of polymers are the high emissivity and the low thermal conductivity of these materials.

To generate the required temperature field there are basically two approaches [1]:

a) passive methods use a heat source located outside the components; heat is deposited in the sample surface thereby driving the heat flow (heat flow thermography);

b) in active methods the volume of the component acts as a distributed heat source due to the hysteresis effect or due to the thermoelastic effect (vibrothermography) [2,3].

The intention of the present work was to compare the two methods in terms of sensitivity and to apply the more successful method for monitoring the development of failure in long fibre reinforced polymers. 


\section{Experimental comparison of methods}

As models of subsurface defects we used holes drilled parallel to the surface. Parameters were diameter, length, and distance to the surface. For heat flow thermography the samples were illuminated on their front surface by two lamps each with $500 \mathrm{~W}$.

For vibrothermography inspection we used stress amplitudes up to $30 \%$ of strength. Comparison of results obtained with both methods are presented in figure 1 for holes of various diameters in polyamide (with and without glass fibres) and in polybutylene

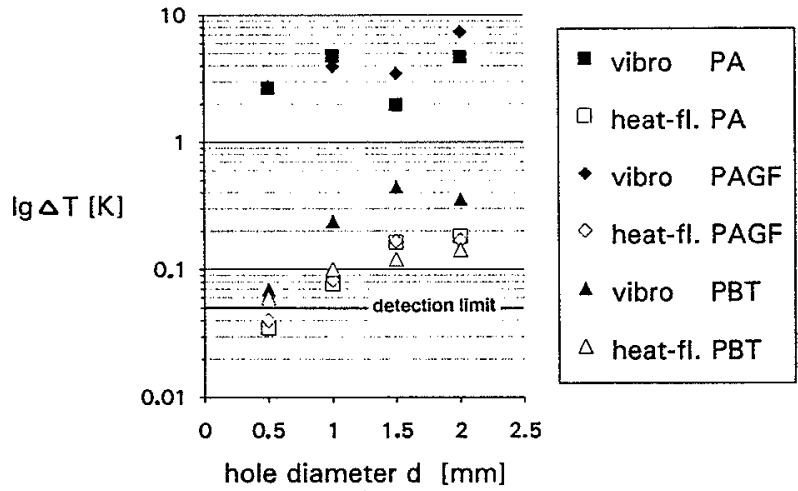

Fig. 1. - Comparison of results from heat-flow and vibrothermography

terephthalate. In heat flow thermography, the detection limit (defined here as temperature increase by $0.05 \mathrm{~K}$ ) was found at a hole diameter of $0.5 \mathrm{~mm}$ for all materials while on the average the effect was much stronger with vibrothermography. The reason for this difference is that in passive methods the heat has to propagate from the surface to the defect and back while only half the path length is involved for the internal heat sources activated in vibrothermography. The material specific behaviour is stronger since the loss angles involved in heat generation are different.

The essential result is that for subsurface defect detection the sensitivity of vibrothermography is better. However, application of heat flow methods is easier and cheaper since no oscillating load is involved. The final decision depends on the specific component.

\section{Monitoring of failure development}

While vibrothermography is a NDE method we used the setup here to monitor sample behaviour under continuously applied cyclic load resulting in a strong temperature increase and, finally, failure. Sample cross section (figure 2) was the same for all long fibre reinforced materials. The temperature field was observed in the vicinity of the hole as a function of time during the stress modulation at $10 \mathrm{~Hz}$ and $30 \%$ strain. 


\subsection{Glass fibre reinforced polymers}

One kind of GFRP laminates had fibre directions of \pm 45 degrees. Colour figure $A^{*}$ shows the temporal development of surface temperature on both sides near the hole and the temperature field at the beginning of the test and close to sample failure.
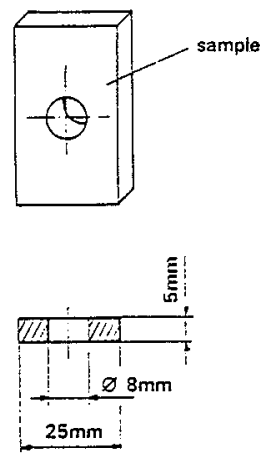

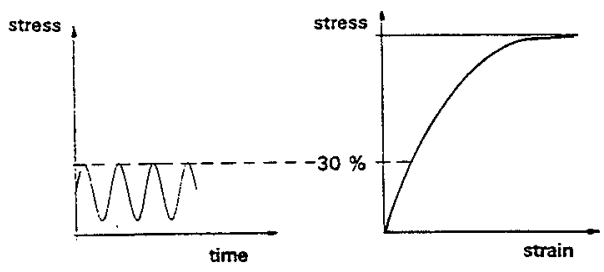

Fig. 2. - Sample geometry and stress modulation for vibrothermography

Obviously the area of heat generation (butterfly-pattern) is always the same.

Other GFRP laminates were uniaxial with orientation along the stress direction. Under the same load pattern the time until failure was more than three times longer, but the temperature curve was much different and the observed temperature pattern was more complicated. The initial thermographic image shows a temperature distribution which agrees with the one expected due to the stress concentration near the hole (colour figure B). After less than one minute the temperature maxima have moved to the 45 degree positions from where they gradually move to the ends of the sample while the temperature near the hole decreases (colour figure $C$ ). The general feature of failure under cyclic load obviously consists of the following steps:

- heat is generated before delamination due to stress gradients in boundary areas,

- heat causes delamination (the temperatures of $80^{\circ} \mathrm{C}$ are observed at the surface),

- loss of boundaries stops heat generation,

- delaminated areas become cold,

- therefore warm areas reveal the front of damage process.

\subsection{Carbon fibre reinforced polymers}

In general the behaviour of CFRP is similar to the one observed for GFRP. For $0^{\circ}$ laminates one finds again temperature propagation along the laminate though the temperature close to the hole does not decrease (colour figure $D$ ). One potential reason is the high thermal conductivity of carbon fibres. For the $\pm 45^{\circ}$ laminate an interesting mechanism was found: from all the thermographic images recorded on tape some are displayed in colour figure $E$ that were obtained in the last seconds before failure. The white spot indicating high temperature jumps from the left side of the hole to the right and back. The behaviour of this hot spot is like a flash moving back and forth (pingpong-effect). The cross-over of temperatures is also clearly displayed in the temperature curves. 


\section{http://dx.doi.org/10.21611/qirt.1992.021}

In terms of the steps mentioned above there is obviously a dynamic instability: if one side of the hole takes more load than the other (e.g. by slight asymmetry of sample or of tensile machine) it becomes warmer, strains and heat generation is stopped due to loss of stress. Thereby the other side is activated until stress is reduced in the hot spot area.

\section{Conclusion}

Vibrothermography is a useful method for polymer inspection due to the large loss angle, high emissivity, and low thermal conductivity (preventing smearing effects of thermal patterns) of these materials. The method is particularly suited to monitor the process of failure development where not only regions of stress and delamination are revealed. It helps also to analyse rapid phenomena involved immediately before failure due to the temperature sensitivity of polymer properties.

\section{REFERENCES}

[1] SUMMERSCALES (J.) - Non-destructive testing of fibre-reinforced plastics composites. Elsevier Appl. Science, London and New York, I, 1987 ; II, 1990.

[2] HENNEKE (E.G.), REIFSNIDER (K.L.), and STINCHCOMB (W. W.) Thermography. An NDI method for damage detection. Journal of Metals, Sept. 1979, p. 11-15.

[3] FISCHER (G.) - Vibrothermographie - ein zerströungsfreies Verfahren zur Verformungsanalyse und Schadensdetektion bei Kunststoffteilen. VDI Berichte 631, VDI Verlag Düsseldorf, 1987, p. 153-162. 